\title{
Institutional Change and Transgender Employment
}

\author{
Alex Redcay \\ Wade Luquet
}

\begin{abstract}
The purpose of this paper is to recommend non-discriminatory policies and practices regarding transgender individuals in the workplace. This paper will summarize workplace discrimination legal cases involving transgender individuals. Specifically, employers can be held financially responsible if they fire or discriminate against transgender individuals on the basis of gender identity and gender expression and can be required to use affirmed pronouns, revise policies, and provide training to employees regarding non-discrimination. Employers cannot discriminate against transgender individuals for transitioning, cannot prevent transgender individuals from using a particular bathroom or locker room, and cannot require employees to medically transition prior to gender identity recognition. Employers can be required to allow medical services related to transgender care. Finally, transgender individuals are a protected class under Title VII. This paper discusses the historical and current legal cases that prevent employment discrimination and proposes policies and practices. Recommendations for social workers include creating a sufficient non-discrimination policy, consulting with experts, becoming recognized on an equality index, educating others by not shaming them, and following the social work code of ethics.
\end{abstract}

Keywords: Transgender, workplace discrimination, advocacy

In the United States, more than 11 million adults identify as lesbian, gay, bisexual, or transgender (LGBT, Newport, 2018). LGBT workers have faced a long and pervasive history of employment discrimination, yet little research has focused on the workplace experiences of transgender employees. Either these individuals are not included in such studies, or they are lumped together with non-heterosexual individuals and viewed similarly (Law et al., 2011). Transgender individuals can identify as heterosexual or as LGB since gender identity is distinctly different from sexual orientation. While there is evidence that transgender and LGB individuals both experience discrimination, the experiences differ greatly. Due to these considerable differences, transgender people facing employment discrimination need more specific legal protections as well as distinct and particular resource supports. Several of the legal cases discussed in this paper involve employers firing transgender individuals because they were transitioning. Transition can involve three types: social (i.e., gender expression, pronoun, name), legal (i.e., identification), and medical (i.e., hormones, surgery). Social transition generally occurs first and legal or medical are not required before employers are required to honor gender identity, pronouns, or a name change (Lambda Legal, 2021).

Title VII of the Civil Rights Act of 1964 prohibits discrimination "because of...sex" (Section 701, k). Despite this, the Act previously failed to support transgender plaintiffs in discrimination cases. The Obama administration broadened protected classes under an executive order to include LGBT persons, but that was weakened in a series of orders in

Alex Redcay, PhD, LCSW, is an Assistant Professor in the Department of Social Work at Millersville University in Lancaster, PA. Wade Luquet, PhD, LCSW, is BSW program director and Professor of Social Work at Gwynedd Mercy University, Gwynedd Valley, PA. 
2019 during the Trump administration. However, in June of 2020, the Supreme Court (2020) ruled that the phrase "because of sex" also included gender identity and sexual orientation (Bostock v. Clayton County). Public support for protections had increased steadily over the years prior to the ruling; businesses have voluntarily adopted policies prohibiting discrimination against LGBT employees, and states and local governments have added sexual orientation and/or gender identity to their nondiscrimination laws and policies (Pizer et al., 2011). Now that protections are inscribed in the law, one might expect major changes in employment discrimination for transgender employees; however, like civil rights laws before this, the change will take time, education, support, and continued legal action. Unfortunately, most discrimination is never legally challenged (Pizer et al., 2011) leaving many discriminatory practices such as loss of job, promotion, income, and bullying by individual companies intact, causing undue hardship for the transgender employee.

Social workers are in a unique position to assist in ending discrimination against transgender employees through education and advocacy. Because of our person-inenvironment education model, we are acutely aware that the environment a person lives and works in has a direct influence on performance and emotional well-being. An environment of acceptance and inclusion can help reduce the dysphoria often experienced by transgender persons as they go through their transition and their own self-acceptance (Apeiranthitou et al., 2019). Yet, work environments are often hostile or unaccepting of transgender employees, resulting in their being ostracized or terminated by the company (Tebbe et al., 2019). This paper reviews current case law that has shaped the present day work environment for transgender employees and makes several recommendations that can be undertaken by social workers working within the work environment or hired as consultants to assist with the culture change necessary for work environments to become safe and affirming for transgender employees and colleagues.

\section{Impact of Discrimination}

Members of the LGBT community experience higher rates of discrimination based on sexual orientation and gender identity than their heterosexual and cisgender counterparts (Kattari et al., 2016). Research suggests that discrimination against this community may not occur equally across all members and that transgender individuals experience an even higher frequency of discrimination. A national survey of 6,500 transgender individuals acknowledged that an adverse employment action, denial of a job or promotion, or termination as a result of their transgender status contributed to elevated symptoms of depression, anxiety, and suicidality (Mizock \& Mueser, 2014; National Center for Transgender Equality [NCTE], 2015). Further, those who lose their job due to workplace bias are six times as likely as the general U.S. population to be living on a household income under $\$ 10,000$ per year and four times as likely to experience homelessness (NCTE, 2015).

Employment discrimination against transgender people creates a wide range of negative effects. Transgender employees consistently report having experienced or witnessed discrimination based on sexual orientation or gender identity. In the largest survey of transgender people to date ( $n=7,500$; Grant et al., 2011), 90\% of respondents 
reported having experienced harassment or mistreatment at work or have taken action to avoid it. In the same survey, $47 \%$ reported having been discriminated against in hiring, promotion, or job retention because of their gender identity. Despite having attended college or gained an academic degree at 1.74 times the rate of the general population ( $47 \%$ vs $27 \%$ ), respondents revealed brutal impacts of discrimination including experiencing unemployment at twice the rate and living in extreme poverty at four times the rate of the general population. Forty-one percent reported attempted suicide (Harrison et al., 2012).

The intersectionality (Crenshaw, 1989) of gender, race, disabilities, and other axes of oppression should be considered as additional levels of discrimination for the transgender person. Each of these layers of discrimination adds additional hardships for the person in transition. For example, although the unemployment rate of transgender persons is double that of the general population, the unemployment rate of transgender people of color is four times that of the general population (Grant et al., 2011). For transgender women of color, loss of employment often means an increase in depression (Jefferson et al., 2013) and higher levels of entry into sex work for income. Sex work may also contribute to an increase in arrest (Nadal et al., 2014) and in the homicide rates of transgender persons of color (Balzer et al., 2012). Numerous high-profile murders of transgender women of color have highlighted significant concerns for this population (Human Rights Campaign [HRC], 2020). For the social worker using the person-in-environment model and working with transgender persons, it is best to keep in mind that discrimination mostly occurs, and is intensified by, multiple, intersectional levels of oppression and all must be recognized and addressed for any social change to be successful.

Supporting the scope of negative workplace experiences, Brewster et al. (2014) conducted a qualitative study with 139 transgender-identified individuals who were employed at the time asked participants open-ended questions related to their experiences transitioning at work. Using a thematic content analysis informed by grounded theory, participants' responses were coded into four main domains: (a) interpersonal issues, (b) intrapersonal factors, (c) systemic and organizational issues, and (d) logistics and planning. Findings highlighted the universality of key areas of stress (e.g., hostile coworkers, gendered spaces, no employee protection policies) and strategies for preparing to transition at work (e.g., informing human resources, identifying allies). In addition, the study highlighted positive aspects of the work environment including supportive co-workers who made the transition easier than expected. Several respondents also reported a positive aspect of becoming advocates for workplace changes at their companies by changing policies for transgender employees and having the opportunity to educate co-workers on transition issues (Brewster et al., 2014). Studies such as these can help businesses and those working to change employment environments understand the effects of negative workplace experiences while understanding positive aspects that can be enhanced to support and empower transgender employees.

\section{Why Advocacy is Needed}

Until the June 2020 Supreme Court decision, there was no comprehensive, federal nondiscrimination law that included gender identity. Until this decision, it was difficult to advocate because the ambiguity of the law allowed states to make their own decisions 
whether transgender was a protected class in employment decisions. According to the 2017 State Equality Index (HRC, 2017), 20 states and the District of Columbia prohibited employment and housing discrimination against transgender people based on gender identity. At the same time, state legislatures are debating and, in some cases, passing legislation designed to prohibit transgender people from accessing public bathrooms that correspond with their gender identity or to create exemptions based on religious beliefs that would allow discrimination against transgender people.

The lack of legal protections for transgender individuals produced drastic increases in unemployment and poverty. The National Transgender Discrimination Survey found that $15 \%$ of respondents were living in severe poverty (household income of less than $\$ 10,000 /$ year; James et al., 2016). The unemployment rate among respondents (15\%) was three times higher than the national unemployment rate (5\%) (James et al., 2016). Being unable to afford basic living necessities can result in homelessness or lead to engagement in underground economies like drug sales or survival sex work, ultimately resulting in an increased risk for violence and/or health complications (NCTE, 2015). With the Supreme Court now ruling on the side of employees and advocates, strides can be made in acquiring equal protection and transgender employment rights potentially resulting in equal pay, a decrease in hostile work conditions, and a decrease in stress for the transgender employee due to concerns related to job loss. However, individuals who are transgender can still be discriminated against by employers with fewer than 15 employees and in venues outside of employment such as housing or public accommodation.

\section{Legal Framework}

Title VII of the Civil Rights Act of 1964 specifically prohibits employers from discriminating on the basis of sex, race, color, national origin, and religion, and is considered a landmark civil rights and U.S. labor law triumph. The Act generally applies to employers with 15 or more employees, including federal, state, and local governments. In 2012, the U.S. Equal Employment Opportunity Commission (EEOC) ruled that employment discrimination on the basis of gender identity or transgender status is prohibited under Title VII. This decision defines "sex" discrimination to include sex stereotyping and discomfort with the fact of an individual's transition or with the perceived change in an individual's sex. In 2014, Attorney General Eric Holder and the Department of Justice adopted a position aligning with the EEOC (US DOJ, 2014). In 2017, Attorney General Jeff Sessions issued a directive withdrawing Holder's position and stating that Title VII should be narrowly interpreted to cover discrimination between "men and women," stating, "Title VII does not prohibit discrimination based on gender identity per se" (Sessions, 2017).

The U.S Constitution does not directly address employment discrimination; however, both the Fifth and Fourteenth Amendments limit the discriminatory power of federal and state governments. The Fifth Amendment explicitly bars depriving individuals of "life, liberty or property" without due process of law. The Fourteenth Amendment prohibits states from violating an individual's rights of due process and equal protection. In the context of employment, these federal constitutional provisions limit the power of the state and federal government to discriminate through unequal treatment of employees, former 
employees, or job applicants based on membership in a group (i.e., race or sex). Historically, the structural relationship between the U.S. Constitution and states' constitutions' civil rights provisions are based on what is called The Supremacy Clause. Simplistically, this clause asserts that state constitutions are only allowed to provide more civil liberties than the federal constitution provides. In practice, legislating civil rights is more complicated, often falling prey to prevailing political parties holding offices and the ideologies of their constituents.

Even though, in some states, specific anti-discrimination laws have not yet been enacted, and employment discrimination or harassment is not technically prohibited, legal progress is being made toward extension of those civil rights. Owing to the unceasing efforts of both individuals and advocacy groups, 20 states, plus D.C., have enacted transgender employment protections. Thus, most states have not enacted such protections.

\section{Transgender Employment Cases}

\section{Historic Rulings}

In Price Waterhouse v. Hopkins (1989), the Supreme Court recognized that employment discrimination based on sex stereotypes (e.g., assumptions and/or expectations about how persons of a certain sex should dress, behave, etc.) is unlawful sex discrimination under Title VII. For the first time, the Supreme Court legally established that gender stereotyping is illegal as sex discrimination for cisgender and transgender individuals. Since that ruling, there have been many legal victories for transgender individuals against employers or other organizations who have discriminated against them based on gender identity or gender expression even for children and youth (Broussard $v$. First Tower Loan LLC, 2015; Department of Fair Employment and Housing v. American Pacific Corporation, 2014; EEOC v. Bojangles Restaurants, Inc., 2016; EEOC v. Deluxe Financial Services Corp., 2015; EEOC, 2015; EEOC v. Lakeland Eye Clinic, P.A., 2015; EEOC v. R.G. \& G.R. Harris Funeral Homes, 2014; Lusardi v. Department of the Army, 2015; Lambda Legal, McCreery v. Don's Valley Market, 2013; Tudor v. Southeastern Oklahoma State University [SOSU], 2017; Vroegh v. Iowa Department of Corrections, 2017).

\section{Gender Identity, Expression, and Pronouns}

Employers can be held financially responsible if they fire or discriminate against transgender individuals on the basis of gender identity or gender expression and can be required to use affirmed pronouns, revise policies, and provide training to employees regarding non-discrimination (Broussard v. First Tower Loan LLC, 2015; EEOC v. Bojangles Restaurants, Inc., 2016; Tudor v. SOSU, 2017). In Broussard v. First Tower Loan LLC (2015), First Tower's Vice President informed Tristan Broussard, a transgender male, that he must dress and act as a female in the workplace because his driver's license indicated an " $F$ " for female (United States Equal Employment Opportunity Commission [EEOC], 2017). First Tower also required Broussard to sign a statement agreeing to act and be treated as a female rather than a male while working for First Tower Loan. When Broussard refused, First Tower fired him. In 2015, Broussard was awarded $\$ 53,000$ in 
damages, and in 2016, First Tower Loan agreed to settle the lawsuit and to implement gender identity protections in the workplace. This decision established that employers should honor the gender identity and expression of the employee regardless of the gender listed on identification (EEOC, 2017). In a similar case, the employer was required to provide training to employees, enter a two-year consent degree, and to change policies regarding gender identity/expression and transgender individuals (EEOC v. Bojangles Restaurants, Inc., 2016).

In a third case, Southeastern Oklahoma State University (SOSU) administrators continually used male pronouns when talking to Dr. Rachel Tudor, who identified as female. She was harassed by her colleagues, was told how to dress and what makeup to wear, and was warned that she should take safety precautions as many people were hostile toward transgender individuals. Despite a positive review from her department committee, SOSU denied her tenure several times. Tudor was the first professor in her department to be denied tenure. She filed a complaint with the EEOC and was subsequently fired by SOSU. In 2017, a federal district court in Oklahoma found that SOSU retaliated against her for the EEOC complaint and that SOSU discriminated against her on the basis of gender identity. Tudor was awarded $\$ 1,165,000$ in damages which is the largest award ever received for transgender employment discrimination. Significantly, this case was one of the first in which gender identity was established as a protected class under Title VII, with the federal courts upholding Title VII's prohibition of discrimination based on sex as also applying to gender identity discrimination. In the past, Title VII cases had historically gone to settlement rather than determining federal questions. Tudor v. SOSU was a substantial win for the transgender community, as it set precedent for future gender identity discrimination cases.

\section{Social Transition}

Individuals who are transgender are a protected class under Title VII so employers cannot discriminate against them for transitioning (Department of Fair Employment and Housing v. American Pacific Corporation, 2014; EEOC, 2015; EEOC v. Lakeland Eye Clinic, P.A., 2015; EEOC v. R.G. \& G.R. Harris Funeral Homes, 2014; Lambda Legal., n.d.-b). Aimee Stephens, a transgender female employed by Harris Funeral Homes, was fired after disclosing her plans to transition from male to female. In 2014, the EEOC sued Harris Funeral Homes, alleging that her firing was in violation of Title VII because Harris funeral home expected Stephens to conform to sex stereotypes. The District Court ruled that transgender status was not a protected class under Title VII but after an appeal, the $6^{\text {th }}$ court ruled that Title VII did include transgender individuals. In response, Harris Funeral Homes petitioned the U.S. Supreme Court to determine whether Title VII's term "sex" includes gender identity. On June 15, 2020, the U.S. Supreme Court ruled that both LGB and transgender individuals are protected under Title VII which is the most significant Supreme Court ruling for transgender individuals ever (Supreme Court of the United States [SCOTUS], 2020; SCOTUS Blog, 2019). 


\section{Restrooms and Medical Transition}

Employers can be held financially responsible if they mandate or prevent transgender individuals from using a particular bathroom or locker room (Department of Fair Employment and Housing v. American Pacific Corporation, 2014; EEOC v. Deluxe Financial Services Corp., 2015; Lusardi v. Department of the Army, 2015; Vroegh v. Iowa Department of Corrections, 2017). The Army prevented Tamara Lusardi, a transgender woman and civilian employee, from using the same restroom as all other female employees and her supervisors continued to use male names and pronouns (EEOC, n.d.; Lusardi v. Department of the Army, 2015). Lusardi filed a formal complaint with the Department of the Army who concluded Lusardi failed to prove any of her claims. Lusardi filed an appeal of that decision with the EEOC and this decision was reversed. The Army was required to grant equal and full access to common female facilities, cease and desist from all discriminatory and harassing conduct, pay $\$ 50,000$ in compensatory damages, provide EEO training to all civilian personnel and contractors working at the agency, provide inperson EEO training to all management officials, and consider appropriate disciplinary action against leaders that discriminated against and/or harassed Lusardi (EEOC, n.d.) This was a precedent-setting decision, in that it is binding on all federal agencies, federal contractors, state and local government employers, as well as all private sector employers with 15 or more employees, as the EEOC's interpretation of Title VII affects all future transgender employee discrimination claims (EEOC, n.d.). Since 2015, there have been several more cases related to transgender individuals in the military that are beyond the scope of this paper. For more information on transgender individuals in the military, see Redcay et al. (2020).

Employers are required to recognize the gender identity of all employees and cannot require employees to medically transition prior to gender identity recognition (Transgender Law Center, 2014). In the case of Department of Fair Employment and Housing $v$. American Pacific Corporation, 2014, Nick Lozano, a transgender male, applied for, and accepted, a position as Operations Technician at AMPAC, a pharmaceutical ingredients manufacturer (Transgender Law Center, 2014). Prior to starting the job, Lozano disclosed his transgender status and that he would be undergoing gender affirmation surgery. The original source used the term "sex reassignment surgery." The more appropriate term today is "gender affirmation surgery." AMPAC reacted by requiring Lozano to use the women's restroom until he completed his surgery. Lozano subsequently declined the job offer. In 2014, the Department of Fair Employment and Housing (DFEH) filed a complaint in California Superior Court on Lozano's behalf, alleging discrimination on the basis of gender identity. Having reached a settlement, the California DFEH issued new guidance in 2016 for California employers indicating that employers cannot require a gender affirmation surgery as a prerequisite to the employer recognizing the employees' gender identity. Sacramento Superior Court held that California's Fair Employment and Housing Act (FEHA) prohibits employers from requiring transgender workers to use restrooms and locker rooms based on their assigned sex at birth (Transgender Law Center, 2014). 


\section{Medical Services and Hormones}

Employers can be required to cover medical services related to transgender care (Department of Fair Employment and Housing v. American Pacific Corporation, 2014; EEOC v. Deluxe Financial Services Corp., 2015; Vroegh v. Iowa Department of Corrections, 2017). In two similar cases, the employer was prohibited from denying transgender adults from receiving medical care that is normally provided to cisgender individuals. Both employees faced discrimination and harassment based on gender identity/expression and bathroom use. The first employee, Britney Austin with the legal assistance of the EEOC won a settlement agreement which required the employer to pay Austin $\$ 115,000$ in damages due to discrimination but also required a three-year consent provision that Deluxe will not make exclusions in their healthcare benefits plan for medically necessary care based on transgender status (EEOC v. Deluxe Financial Services Corp., 2015). In a second similar case, Jesse Vroegh, a transgender male nurse at the Iowa Correctional Institution for Women (ICIW), alleged that ICIW denied necessary medical treatment because he is transgender (Vroegh v. Iowa Department of Corrections, 2017). Wellmark Blue Cross, Vroegh's employer-sponsored medical insurance provider, denied him health care coverage for medically necessary surgery even though it provides coverage for similar procedures for non-transgender employees. The ACLU of Iowa filed a complaint with the Iowa Civil Rights Commission (ICRC) and in February 2019, Vroegh was awarded $\$ 120,000$ because they found that he was denied insurance coverage for medically necessary surgery solely because he was transgender. This decision established that employers or their insurance companies are not permitted to deny medically necessary medical care, including surgery, for transgender individuals.

In another case, (Lawrence v. Office of Personnel), Marc Lawrence, a transgender male retiree of the Federal Bureau of Prisons, was denied health coverage for hormone-related care, including hormone prescriptions and visits to an endocrinologist, despite such care being routinely covered for cisgender employees and retirees (Lambda Legal., n.d.-a). Citing a blanket health plan exclusion refusing coverage for all care related to gender affirmation transition, Lawrence's care was denied. In 2014, Lambda Legal filed a complaint with the EEOC on behalf of Lawrence, arguing that the OPM's health plan's exclusion violates Title VII protections against discrimination based on sex. The judge issued a tentative ruling in favor of Lawrence, and Lambda Legal requested a Final Agency Decision (FAD) from OPM. OPM found in its own favor, rejecting Lawrence's claims. In June 2016, Lambda Legal filed an appeal with the EEOC. The case remains open.

\section{Action Recommendations}

Without a doubt, the workplace has changed for employees who are transgender. It is now increasingly hospitable because of greater societal understanding and at the same time increasingly hostile from those who fear the change and do not know how to react or treat their transgender colleagues and employees. Certain groups are at higher risk for difficulty. Transgender women of color have significantly higher rates of harassment, bullying and even murder due to the intersectionality of race and gender identity (HRC, 2020). In spite of forward progress and regressive reactions, case law and inclusive employee policies are moving the arc of justice increasingly toward protection against discrimination for 
transgender persons in the workplace. And now that the Supreme Court has weighed in to protect transgender persons from work discrimination, the door is opened for definitive actions by companies and transgender advocates, including social workers. The real shift toward non-discrimination will take a work culture change that not only accepts but affirms the right of the transgender person to work in a safe environment.

\section{Revise Non-Discrimination Policies}

Many organizations have a non-discrimination policy as part of their employee handbooks, but many do not include gender identity and expression. In addition, organizations are unaware of their requirements to honor the gender identity, affirmed pronoun, and name of all employees regardless of the status of transition. The majority of states $(\mathrm{n}=31)$ fail to have sufficient non-discrimination laws for transgender individuals, so employer policies are important to address the gap in protection (Movement Advancement Project, 2017). Employers are also required to permit medical services and bathroom use regardless of transgender status. Organizations choosing to address these issues could draft a non-discrimination policy that is inclusive and reflective of the current state of the legal environment. An example of an inclusive non-discrimination policy might be:

This organization is an equal opportunity employer and does not practice, condone, tolerate, facilitate, or collaborate with any discrimination on the basis of race, color, age, ethnicity, sex, gender identity, gender expression, pregnancy, religion, creed, sexual orientation, marriage or partner status, national origin, ancestry, citizenship status, disability, military service or affiliation, financial status, or genetic information. This organization acts to prevent and eliminate discrimination in policies, practices, work assignments, hiring or firing of staff, compensation, selection of volunteers, vendors, and provision of services. We are committed to providing an inclusive and welcoming environment for all staff, clients, volunteers, subcontractors, and vendors.

There is little proof that a non-discrimination policy will by itself change a work culture and may in fact increase discrimination during the hiring phase (Valfort, 2018). However, an inclusive non-discrimination policy is a good start and is a statement that will lead the change as a company mission statement. Definitive action is needed to meet the workplace mission of non-discrimination toward transgender employees. These policies require actions and enforcements to counter prejudices and bias toward targeted groups (Valfort, 2018).

\section{Consult With Experts}

One way of moving a policy toward implementation is by consulting with experts trained to facilitate organizational change. Organizations that are responsive to the changing culture can work with experts to update and assist them with education of employees and understanding of legal policies. Organizations that fail to learn and practice non-discriminatory actions may be engaged in lawsuits, engendering negative publicity, a tremendous amount of wasted time, and exorbitant legal fees. Many national organizations, including the National Center for Transgender Equality, Transgender Law Center, American Civil Liberties Union, Lambda Legal, and the Equal Employment Opportunity 
Commission provide advice regarding employment non-discrimination policies and practices. All websites are free to review and generally provide examples and helpful advice.

\section{Become Recognized}

One place to begin is to work toward meeting the criteria for and becoming recognized by the HRC effort for safe and non-discriminatory workplaces for the LGBT community. The Healthcare Equality Index, Campus Pride Index, and the Corporate Equality Index are just a few rating systems set up by HRC that share a similar goal to identify organizations that recognize and respect LGBT individuals. Each index provides an assessment for organizations to review their policies and procedures to ensure best practices. For example, healthcare organizations would be expected to meet the specific criteria in the following areas: Non-Discrimination and Staff Training, Patient Services and Support, Employee Benefits and Policies, Patient and Community Engagement, and Responsible Citizenship. To meet these criteria, health care organizations would have to hold regular trainings for employees on LGBT issues, provide equal health care benefits for employees including transition benefits for transgender employees, train staff to work with LGBT patients, hold events supporting the LGBT community, and allocate resources to LGBT advocacy groups, as well as other criteria described on their web site (HRC, n.d.-b).

For corporations to receive a high score in the Corporate Equity Index, employers must offer parity between different- and same-sex spouses and have coverage available for domestic partners of enrollees, must remove transgender exclusions from all benefits plans, and must include LGBT suppliers as part of their supplier diversity program (if such a program is in existence; HRC, n.d.-a). These indexes and the criteria established for inclusion as a safe workplace for LGBT employees can offer employers an outline of the changes needed in their corporate culture to protect the rights of their transgender employees.

\section{Advocate by Educating, Not Shaming}

Culture change in the workplace is often filled with anxiety and fear until the change become ordinary and part of the organizations story (Burk, 2019). For some, especially those coming from more conservative backgrounds, the change and accompanying anxiety toward inclusivity can induce adverse reactions resulting in discriminatory behavior. Rather than shame those who are fearful of what they do not know, it is more prudent to educate them. It is often said that fear of the "other" is rooted in the ignorance of the "other." Getting to know the other lessens fear. This might start as an educational program as advocated by the HRC and then lead to exposure to the transgender person through trans advocates who can come into the workplace to meet those who would like to know more. A simple internet search will reveal multiple agencies and universities that provide workplace transgender equity training. One example in the Philadelphia area is the Mazzoni Center, a comprehensive center that offers multiple services for transgender individuals including trainings for the workplace (Mazzoni Center, 2021). 
There are plenty of ill-informed ideas people hold, including that someone who is transgender is mentally ill, a cross dresser who likes to wear men's or women's clothing, or wants to get into the bathroom of the others. Employees can be enlightened by exposure to transgender individuals who can speak their truth and expose anxious employees to the reality that their desire to live their gender identity is as natural as each of them living their gender identity. Many persons hold the false idea that being transgender is a mental illness because of the recent addition in the DSM 5 of Gender Dysphoria (American Psychological Association, 2013), a diagnosis added to describe the stress transgender persons experience during their transition from the change and non-acceptance of others. In an inclusive and accepting environment, Gender Dysphoria is lessened (Martinez et al., 2017). A safe workplace for transgender individuals is part of the overall solution to the depression and anxiety transgender individuals experience during transition.

\section{Ethical Implications for Social Workers}

In alignment with their Code of Ethics (COE), members of the National Association of Social Workers (NASW, 2017) are tasked with exerting all effort toward meeting basic human needs, with a specific focus on those who are threatened, unprotected, and persecuted. Building and fostering social justice and change on behalf of the oppressed is virtually mandated for those in the service of social work. For the transgender community, obstacles to human rights, including employment barriers, far exceed the criteria for the definition of a vulnerable and often brutally oppressed population.

At the macro level, social workers are called upon in the COE standard 6.04 (a) (NASW, 2017) to take Social and Political Action:

Social workers should engage in social and political action that seeks to ensure that all people have equal access to the resources, employment, services, and opportunities they require to meet their basic human needs and to develop fully.

Fortunately, NASW, representing 120,000 social workers, joined other advocacy agencies in filing an Amici Curiae (Friend of the Court) brief (Brief for Southern Poverty Law Center et al. as Amici Curiae Supporting Respondents Bostock v. Clayton County, 2019) to the Supreme Court for the Bostock v. Clayton County case that resulted in the historic June 2020 decisions recognizing that "on the basis of sex" also included sexual orientation and gender identity. The brief is a comprehensive document backed by peer-reviewed research and case law that outlines the dangers of workplace discrimination. Friends of the Court briefs are one way the profession of social work can with other organizations to advocate at the macro level for fairness in the legal system for transgender persons. NASW responded to this case in a manner in keeping with the COE which states in Standard 6.04(b) (NASW, 2017): (b) Social workers should act to expand choice and opportunity for all people, with special regard for vulnerable, disadvantaged, oppressed, and exploited people and groups.

At the mezzo level of practice, social workers and social work administrators must assure that their own organizations and agencies are practicing non-discriminatory hiring practices. A formal non-discrimination policy that includes gender identity as a category 
should be on file and presented to new and existing employees. This would be in alignment with Standard 3.07(d) (NASW, 2017):

Social work administrators should take reasonable steps to ensure that the working environment for which they are responsible is consistent with and encourages compliance with the NASW Code of Ethics. Social work administrators should take reasonable steps to eliminate any conditions in their organizations that violate, interfere with, or discourage compliance with the Code.

At the micro level, social workers are ethically obligated to promote the well-being of their client. Standard 1.01 (a) (NASW, 2017) states "Social workers' primary responsibility is to promote the well-being of clients. In general, clients' interests are primary." When clients find themselves in job situations where they are being harassed, demoted, passed over for promotion, or terminated based on their gender identity, their well-being is diminished and there is an obligation for the social worker to intervene or advocate. It may not be appropriate for the social worker to intervene or advocate personally because of confidentiality, self-determination or self-efficacy reasons, so support, encouragement, and information may be the best course of action for the social worker. Encouraging the client to initially follow job protocols, talking to the offending person, or going to the Human Resources administrator, may be the first steps. Should the situation not be satisfied, the social worker can help the client take the matter to the next level by helping the aggrieved employee build a case to take to the Equal Employment Opportunity Commission (EEOC). This is a necessary step prior to a lawsuit with the EEOC acting as a mediator to settle the dispute prior to any lawsuit.

With the law now on the side of the transgender person, the person can step forward to file a complaint with less fear of losing a job. For employers who choose to disregard the law and terminate the transgender person from their job, the social worker has an obligation to assist the person to find legal help, including low-cost legal help for those who cannot afford a lawyer. The social worker should advocate not only to foster the culture change that will be gradual since the 2020 ruling, but also because transgender persons who lose their jobs, are not promoted, or are not hired because of their gender identity lose income that can serve as their bridge out of poverty. The social worker should advocate for legal protection related to transition, harassment issues, job security, promotion opportunities, and bathroom access. Beginning with the end in mind (Covey, 2004), the goal should be equal job opportunities, equal promotion opportunities, equal job security, and an opportunity for a livable wage for transgender clients.

\section{Conclusion}

Violence, poverty, stigma, harassment, the lack of legal protections, and other roadblocks to public resources faced by the transgender community are conditions that the social work community must endeavor to remedy. Along with the implementation of gender-affirming counseling, social workers' advocacy for diversity and inclusion in the workplace could ensure these ideals become foundational to a company's core values. Moreover, creating inclusive policies could help retain valuable employees and affirm them as respected members of their workplace community. According to the National 
LGBT Task Force, transgender individuals who come out in a supportive workplace not only reduce the stress of having to hide their true selves, but are more productive, have higher self-esteem, have authentic and close relationships with their colleagues, customers and clients, and are ultimately better able to live genuine and whole lives (James et al., 2016).

Although more than half a century has passed since the Civil Rights Act was enacted, employment discrimination persists. This article raises and addresses critical issues regarding the unanswered question of how social workers and organizational researchers and practitioners can contribute to eradicating employment discrimination toward transgender employees. This article considers discrimination reduction tactics through discussing current legal strategies aimed at reducing discrimination beyond racial, ethnic, and gender differences. Education and advocacy by social workers will be an integral part of the change to eliminate employment discrimination for transgender persons.

The law has only recently evolved to include all rights of transgender individuals in the workplace. Advocating for their civil and human rights is the responsibility of our society, and social workers are well-positioned to advocate at both the micro, mezzo, and macro levels. This includes eliminating barriers that allow discrimination in the workplace and other areas of public life; creating systems of support at the municipal, state, and federal levels that meet the needs of transgender people; and changing federal, state and local laws to acknowledge the humanity and, subsequently, the equal rights of transgender people. For the transgender community to continue to evolve, public education, understanding, and acceptance of this community are crucial.

\section{References}

American Psychological Association. (2013). Gender dysphoria. In Diagnostic and statistical manual of mental disorders (5th ed.). Author. https://doi.org/10.1176/appi.books.9780890425596

Apeiranthitou, V., Thomas, G, \& Louka, P., (2019). Gender dysphoria: A critical discussion of the understanding and treatment of gender dysphoria. Dialogues in Clinical Neuroscience \& Mental Health, 2(1), 72-80. https://doi.org/10.26386/obrela.v2i1.110

Balzer, C., Hutta, J.S., Adrian, T., Hyndal, P., \& Stryker, S. (2012). Transrespect versus transphobia worldwide: A comparative review of the human-rights situation of gender-variant/trans people. https://tgeu.org/human-rights-situation-of-gendervarianttrans-people-a-comparitive-review/

Brewster, M. E., Velez, B. L., Mennicke, A., \& Tebbe, E. (2014). Voices from beyond: A thematic content analysis of transgender employees' workplace experiences. Psychology of Sexual Orientation and Gender Diversity, 1(2), 159-169. https://doi.org/10.1037/sgd0000030

Brief for Southern Poverty Law Center et al. as Amici Curiae Supporting Respondents Bostock v. Clayton County. (2019). Nos. 17-1618, 17-1623, 18-107

Broussard v. First Tower Loan LLC, E.D. La. (2015). Civ. No. 2:15 cv 01161 CJB SS 
Burk, J. E. (2019). The only constant is change: Developing a compelling story to enable organizational transformation. International Journal of Knowledge, Culture \& Change in Organizations: Annual Review, 19(1), 1-6. https://doi.org/10.18848/14479524/cgp/v19i01/1-6

Civil Rights Act of 1964 (Pub.L. 88-352, 78 Stat. 241, enacted July 2, 1964)

Covey, S. R. (2004). The 7 habits of highly effective people: Restoring the character ethic (Rev. ed.). Free Press.

Crenshaw, K. (1989). Demarginalizing the intersection of race and sex: A black feminist critique of antidiscrimination doctrine feminist theory and antiracist politics. University of Chicago Legal Forum, 1989(1), 139-167.

Department of Fair Employment and Housing v. American Pacific Corporation. (2014). (No. 34-2013-00151153-CU-CR-GDS).

Equal Employment Opportunity Commission [EEOC] v. Bojangles Restaurants, Inc. (2016). (E.D. N.C., Civ. No. 5:16-cv-00654-BO).

EEOC. (n.d.). Decision: Lusardi v. Department of the Army [Appeal No. 0120133395]. https://www.eeoc.gov/sites/default/files/migrated files/decisions/0120133395.txt

EEOC. (2015). Lakeland eye clinic will pay $\$ 150,000$ to resolve transgender / sex discrimination lawsuit. https://www.eeoc.gov/eeoc/newsroom/release/4-13-15.cfm

EEOC v. Deluxe Financial Services Corp. (2015). (D. Minn., Civ. No. 0:15-cv-02646ADM-SER, filed June 4, 2015, settled January 20, 2016).

EEOC v. Lakeland Eye Clinic, P.A. (2015). (M.D. Fla., Civ. No. 8:14-cv-2421-T35 AEP) filed Sept. 25, 2014, settled April 9, 2015).

EEOC v. R.G. \& G.R. Harris Funeral Homes Inc. (2014). (E.D. Mich., Civ. No. 2:1cv 13710- SFC-DRG)

Grant, J. M., Mottet, L., Tanis, J. E., Harrison, J., Herman, J., \& Keisling, M. (2011). Injustice at every turn: A report of the National Transgender Discrimination Survey. National Center for Transgender Equality. https://www.transequality.org/sites/ default/files/docs/resources/NTDS Report.pdf

Harrison, J., Grant, J., \& Herman, J. L. (2012). A gender not listed here: Genderqueers, gender rebels, and otherwise in the National Transgender Discrimination Survey. https://escholarship.org/uc/item/2zj46213

Human Rights Campaign [HRC]. (2017). State Equality Index: A Review of state legislation affecting the lesbian, gay, bisexual, transgender and queer community and a look ahead in 2018. https://assets2.hrc.org/files/assets/resources/HRC-2017-reportFINAL-2.pdf?.ga=2.188312680.1381324499.1546526348-1907367825.1544109666

HRC. (2020). Dismantling a culture of violence: Understanding anti-transgender violence and ending the crisis. https://assets2.hrc.org/files/assets/resources/2018Anti 
$\underline{\text { TransViolenceReportSHORTENED.pdf? ga }=2.216540630 .1128794973 .1595358740}$ $-1411897819.1595358740$

HRC. (2021). HRC global workplace equity programs. https://www.hrc.org/resources/hrc-global-workplace-equality-programs

HRC. (n.d.-a). Corporate Equality Index 2020. www.hrc.org/campaigns/corporateequality-index

HRC. (n.d.-b). Healthcare Equality Index 2020. https://www.hrc.org/resources/healthcareequality-index

James, S. E., Herman, J. L., Rankin, S., Keisling, M., Mottet, L., \& Anafi, M. (2016). The Report of the 2015 U.S. Transgender Survey. National Center for Transgender Equality. https://ransequality.org/sites/default/files/docs/usts/USTS-Full-ReportDec17.pdf

Jefferson, K., Neilands, T. B., \& Sevelius, J. (2013). Transgender women of color: Discrimination and depression symptoms. Ethnicity and Inequalities in Health and Social Care, 6(4), 121-136. https://doi.org/10.1108/eihsc-08-2013-0013

Kattari, S. K., Whitfield, D. L., Walls, N. E., Langenderfer-Magruder, L., \& Ramos, D. (2016). Policing gender through housing and employment discrimination: Comparison of discrimination experiences of transgender and cisgender LGBQ individuals. Journal of the Society for Social Work and Research, 7(3), 427-447. https://doi.org/10.1086/686920

Lambda Legal (2021). Transgender Workplace Rights. https://www.lambdalegal.org/know-your-rights/article/trans-workplace

Lambda Legal. (n.d.-a). Lawrence v. Office of Personnel Management. https://www.lambdalegal.org/in-court/cases/fl lawrence-v-opm

Lambda Legal. (n.d.-b). McCreery v. Don's Valley Market. https://www.lambdalegal.org/in-court/cases/mccreery-v-dons-valley-market

Law, C. L., Martinez, L. R., Ruggs, E. N., Hebl, M. R., \& Akers, E. (2011). Transparency in the workplace: How the experiences of transsexual employees can be improved. Journal of Vocational Behavior, 79(3), 710-723. https://doi.org/10.1016/j.jvb.2011.03.018

Lusardi v. Department of the Army. (2015). (No. 0120133395).

Martinez, L. R., Sawyer, K. B., Thoroughgood, C. N., Ruggs, E. N., \& Smith, N. A. (2017). The importance of being "me": The relation between authentic identity expression and transgender employees' work-related attitudes and experiences. Journal of Applied Psychology, 10(2), 215-226. https://doi.org/10.1037/ap10000168

Mazzoni Center. (2021). Education and professional development. https://www.mazzonicenter.org/supportive-services/education-and-professionaldevelopment 
Mizock, L., \& Mueser, K. T. (2014). Employment, mental health, internalized stigma, and coping with transphobia among transgender individuals. Psychology of Sexual Orientation and Gender Diversity, 1(2), 146-158. https://doi.org/10.1037/sgd0000029

Movement Advancement Project [MAP]. (2017, February). Mapping transgender equality in the United States. https://www.lgbtmap.org/mapping-trans-equality

Nadal, K. L., Davidoff, K. C., \& Fujii-Doe, W. (2014). Transgender women and the sex work industry: Roots in systemic, institutional, and interpersonal discrimination. Journal of Trauma \& Dissociation: The Official Journal of the International Society for the Study of Dissociation (ISSD), 15(2), 169-183. https://doi.org/10.1080/15299732.2014.867572

National Center for Transgender Equality. (2015). 2015 U.S. Transgender Survey. http://www.ustranssurvey.org/

National Association of Social Workers [NASW]. (2017). NASW code of ethics. https://www.socialworkers.org/About/Ethics/Code-of-Ethics/Code-of-Ethics-English

Newport, F. (2018). In U.S., Estimate of LGBT Population Rises to 4.5\%. https://news.gallup.com/poll/234863/estimate-lgbt-population-rises.aspx

Pizer, J. C., Sears, B., Mallory, C., \& Hunter, N. D. (2011). Evidence of persistent and pervasive workplace discrimination against LGBT people: The need for federal legislation prohibiting discrimination and providing for equal employment benefits. Loyola of Los Angeles Law Review, 45(3), 715-780. https://escholarship.org/uc/item/3wf4t3q9

Price Waterhouse v. Hopkins, 490 U.S. 228. (1989). (Case No. 87-1167)

Redcay, A., Luquet, W., \& Hagan, R. (2020). Military service for transgender United States soldier. Journal of Human Rights and Social Work, 5, 191-200. https://doi.org/10.1007/s41134-020-00129-x

Sessions, J. (2017). Revised treatment of transgender employment discrimination claims under Title VII of the Civil Rights Act of 1964 [Memorandum]. Office of the Attorney General (OAG). https://assets.documentcloud.org/documents/4067437/ Sessions-memo-reversing-gender-identity-civil.pdf

Supreme Court of the United States [SCOTUS]. (2020). Syllabus: Bostock v. Clayton County, Georgia. https:/www.supremecourt.gov/opinions/19pdf/17-1618_hfci.pdf

SCOTUS Blog. (2019). R.G. \& G.R. Harris Funeral Homes Inc. v. Equal Employment Opportunity Commission. https://www.scotusblog.com/case-files/cases/r-g-g-rharris-funeral-homes-inc-v-equal-opportunity-employment-commission/

Tebbe, E. A., Allan, B. A., \& Bell, H. L. (2019). Work and well-being in TGNC adults: The moderating effect of workplace protections. Journal of Counseling Psychology, 66(1), 1-13. https://doi.org/10.1037/cou0000308

Transgender Law Center. (2014). Victory for transgender workers in California. https://transgenderlawcenter.org/archives/10033 
Tudor v. Southeastern Oklahoma State University [SOSU]. (2017). (No. CIV-15-324-C) https://www.laborandemploymentlawcounsel.com/wp-content/uploads/sites/224/ 2017/11/Tudor-v-SE-Oklahoma-State-U-No-15-324-C-WD-OK-10-26-2017.pdf

United States Department of Justice [US DOJ]. (2014). Attorney General Holder directs department to include gender identity under sex discrimination employment claims. https://www.justice.gov/opa/pr/attorney-general-holder-directs-department-includegender-identity-under-sex-discrimination

United States Equal Employment Opportunity Commission [EEOC]. (2017). First Tower Loan Settles EEOC sex discrimination suit. https://www.eeoc.gov/eeoc/newsroom/release/10-6-17.cfm

Valfort, M. A. (2018). Do anti-discrimination policies work? IZA World of Labor, 450, 1 12. https://wol.iza.org/uploads/articles/450/pdfs/do-anti-discrimination-policieswork.pdf? $v=1$

Vroegh v. Iowa Department of Corrections (2017). (No. LACL138797)

Author note: Address correspondence to Alex Redcay, Department of Social Work, Millersville University, Millersville, PA, 17551. Email: alex.redcay@millersville 